\begin{abstract}
We contend that harvest is a misleading term when referring to wild organisms removed from natural systems and suggest that fishery professionals reserve the word for aquaculture products. When referring to wild stock extraction, replacing the word harvest with catch removes the implication of extractor entitlement, better indicates the fishery product source, and does not distract from the issue of bycatch.
\end{abstract}

\title{
Use of the term harvest when referring to wild stock exploitation
}

\author{
James A. Bohnsack \\ Laura Jay W. Grove \\ Joseph E. Serafy (contact author) \\ Email address for contact author: joe.serafy@noaa.gov \\ Southeast Fisheries Science Center \\ National Marine Fisheries Service, NOAA \\ 75 Virginia Beach Drive \\ Miami, Florida 33149
}

The fish harvest is not a harvest produced by human labour. It is Nature's gift—some would say God's gift—to humanity (Archer, 1944).

Words matter in all walks of life, including in fishery science. As professionals, we strive to communicate information clearly with many audiences, especially the public. Since at least the early 19th century (according to a search for the use of fish harvest during 1800-2019 in the Google Books Ngram Viewer, available from website, accessed August 2020; Michel et al., 2011), harvest has been used somewhat interchangeably with catch and landings. Likewise, harvesting has been a synonym for fishing or collecting biota from natural waters. The glossary of fishery terms published by our own organization, the National Marine Fisheries Service, is replete with the word harvest when referring to removal of wild fish (NMFS, 2006). Certainly, dictionary definitions allow for the use of harvest (in noun and verb form) to apply to a given biomass extracted from a natural system, and to the act of gathering that biomass. However, primary dictionary definitions of harvest (Merriam-Webster ${ }^{1}$ ) and

\footnotetext{
${ }^{1}$ Merriam-Webster. 2020. Harvest. MerriamWebster.com. [Available from website, accessed August 2020.]
}

harvesting (Merriam-Webster ${ }^{2}$ ) typically evoke agriculture, and we feel such definitions transmit several connotations that are subtlety misleading, particularly to non-practitioners. Here, we suggest that fishery professionals reserve the word harvest for reference to fish, invertebrates, and algae produced through aquaculture, and we explain why its usage makes us wince a little when it is applied to wild catches.

In fisheries, catch constitutes all organisms permanently or temporarily extracted from natural ecological communities, and landings are the portion of catch retained. Wild fish populations are not crops that were sowed and nurtured by people, for people. Therefore, labelling wild catches as harvests attaches undue human entitlement to the donor populations and the natural ecosystems of which they are a part. Typically, what is extracted comes from populations that have existed for millennia, before human extraction began, and that would likely thrive well into the future were they not depleted by fishing or anthropogenic modification of their habitats. They persist in spite of humans, not because of humans, with most modern examples of successful

\footnotetext{
${ }^{2}$ Merriam-Webster. 2020. Harvesting. Merriam-Webster.com. [Available from website, accessed August 2020.]
} 
fishery management ensuing from measures taken to stem serious damage previously done.

We suggest that fisheries terms should reflect the fundamental differences between wild and cultured stocks. To use terrestrial analogies, hunters hunt and kill game, and to say they harvest them has been criticized as inaccurate and euphemistic (McWilliams, 2011). Likewise, fishermen hunt and catch fish, they do not harvest them. Farmers harvest cultured crops: vegetables, grains, and fruits from the fields or orchards that they planted and eggs and meat from the domesticated animals that they raised. When fish farmers garner the fish, invertebrates, or algae they have raised, we do not call that act fishing nor do we call their yield a catch. We feel harvest and harvesting are appropriate for aquaculture products. In aquaculture operations, substantial resources are devoted to selection, health, and nutrition of broodstock. In contrast, wild stock management typically focuses on controlling total fishing mortality on a given population to avoid overfishing, especially over-removal of the largest, oldest, most fecund individuals that sustain fisheries. In other words, fishery managers protect wild stocks mostly from humans, not from other natural predators, disease, starvation, and weather extremes. Cultured organisms stocked in, and subsequently retrieved from, natural systems occupy a gray area with the term harvest being less appropriate the longer they are at liberty and become integrated components of the ecosystem.

Differentiating terminology between wild caught and aquaculture fish species can have broader implications by tracing seafood to its source. The how, where, and when fish are removed, processed, transported, and managed prior to purchase are unclear, particularly in comparison with those aspects of other food sectors. In recent years, consumers have become more concerned with the path food takes to their plate. Traceable terminology helps to distinguish a product's source, allowing consumers to make informed decisions related to their health, conservation values, or desire to support their local economy. Moreover, for fishery professionals, distinct terminology simplifies sorting data for management and easily identifies contributions to the global fish market. In some ways, this identification of sources reinforces an implicit decision by the Food and Agriculture Organization to use the terms capture fisheries and aquaculture for the most part keeping harvest out of their fishing terminology.

Fishermen engage in fishing for many purposes, including consumption and recreation in addition to commerce. Although fishermen invest heavily in their fishing vessels, gear, fuel, licenses, etc., and fishery professionals invest in stock assessment and management plans, they do not directly invest, at least not to the degree a farmer does, in the ecosystem from which biomass is extracted. Fishery managers aim to maximize economic benefit accrued from exploitation of targeted species, but for most untargeted species, often no care per se is provided (i.e., no regulations). We acknowledge that fishermen are compelled, sometimes at substantial cost, by fishery management measures (or their own ethical codes) to modify how, when, how much, and what they land from the ecosystems (e.g., through bag, minimum size, gear, season, and area limitations). However, we disagree that taking on these conservation burdens justifies use of the term harvest for what was hunted and removed from a natural system. In addition, when harvest is applied to wild stocks, it diverts attention from the issue of bycatch in many fisheries. The benign term harvest narrows the focus on the landed (or hooked) biomass of target species as opposed to the biomass and diversity actually affected (i.e., untargeted species or size classes killed or injured), which can be significant and even exceed landings in some fisheries.

Likely guided by the National Marine Fisheries Service glossary (NMFS, 2006), nongovernmental organizations, policy makers, and the U.S. legal system (Auslander and Tipple, 2020) similarly apply harvest to wild fish extraction. Indeed, the Southeast Fisheries Science Center, our own part of the National Marine Fisheries Service, has a unit labelled Harvesting Systems, when in fact, much of its research emphasis has been on minimizing bycatch without reducing target catch rates. Fishing Systems would be a more appropriate label. More examples of harvest and harvesting being applied to catches or fishing, with suggested replacement text, include the following: harvest season is open (i.e., fishing season is open) and Anglers can harvest 2 red snapper per day (i.e., Anglers can land, retain, or possess 2 red snapper per day).

For us, simple substitution of the word catch for harvest and of fishing for harvesting when referring to wild stocks is a step toward accuracy, better indicates the source of a fishery product, and removes any implication that a natural population's production is due to, or owed to, those exploiting it. As fishery professionals, we have a duty and obligation to communicate with accuracy and clarity, particularly to the public. In that regard, using harvesting as a euphemism for fishing is not helpful. Among our colleagues, we doubt harvest control rules will become catch control rules or that harvest recommendations will become catch recommendations any time soon. But we wish they would.

\section{Literature cited}

Archer, J. K.

1944. Address in reply. New Zealand Parliamentary Debates 264:416-418. [Available from website.]

Auslander, J. M., and K. A. Tipple.

2020. Fifth circuit finds National Marine Fisheries Service has no authority to regulate aquaculture. National Law Review, 12 August 2020. [Available from website.]

McWilliams, J. E.

2011. Hunting for euphemisms: how we trick ourselves to excuse killing. Atlantic, 21 December 2011. [Available from website.]

Michel, J.-B., Y. K. Shen, A. P. Aiden, A. Veres, M. K. Gray, W. Brockman, The Google Books Team, J. P. Pickett, D. Hoiberg, D. Clancy et al.

2011. Quantitative analysis of culture using millions of digitized books. Science 331:176-182. Crossref

NMFS (National Marine Fisheries Service).

2006. NOAA Fisheries glossary, rev. ed. NOAA Tech. Memo. NMFS-F/SPO-69, 61 p. 